\title{
The effect of pulmonary rehabilitation on dyspnea and factors related to dyspnea in lung transplantation candidates
}

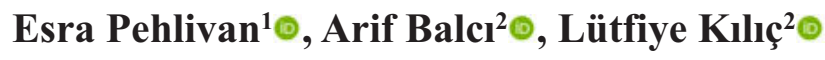 \\ ${ }^{1}$ Department of Physical Therapy and Rehabilitation, University of Health Sciences, Faculty of Health Sciences, Istanbul, Turkey \\ ${ }^{2}$ Department of Pulmonary Rehabilitation, University of Health Sciences, Yedikule Chest Diseases and Thoracic Surgery Training and \\ Research Hospital, İstanbul, Turkey
}

\section{ABSTRACT}

Objectives: Lung transplantation is the last treatment option when conservative treatment is not effective in individuals with terminal stage lung disease. Dyspnea is the primary symptom affecting quality of life in these patients. In our study, the effects of Pulmonary Rehabilitation (PR) on dyspnea and factors related with dyspnea were investigated in lung transplant candidates.

Methods: Patients who were in the lung transplant waiting list and completed the 3-month PR program were included in the study. Study result measurements: 6-minute walk test distance (6MWD), lung functions (FEV1, FVC), respiratory muscle strength (MIP, MEP), quadriceps femoris muscle strength as measured by digital dynanometer, hand grip force measured by hand dinanometer (HG) and modified Modified Medical Research Council (mMRC) dyspnea scale.

Results: A total of 47 patients were included in the study. After PR, 6MWD $(p<0.0001)$, MIP $(p<0.0001)$, $\operatorname{MEP}(p<0.0001)$, HG $(p<0.0001)$ and $\operatorname{mMRC}(p<0.0001)$ improvements were detected. There was no statistically significant relationship between the decrease in $\mathrm{mMRC}$ and the amount of change occurring in other outcome measurements $(p>0.05)$.

Conclusions: According to the results of our study, PR has a positive effect on exercise capacity, peripheral and respiratory muscle strength and dyspnea in lung transplant candidates. But there was no relationship between these positive developments and dyspnea. There is a need for studies investigating the effects of different clinical features on rehabilitation outcomes.

Keywords: lung transplantation, dyspnea, exercise, muscle strength, rehabilitation

\section{I}

$\mathrm{n}$ lung transplantation candidates, the advanced lung pathology causes dyspnea and exercise limitation [1]. Exercise intolerance and dyspnea cause prolonged inactivity and consequently peripheral muscle weakness [2]. In these patients, despite the optimal medical treatment given to relieve symptoms during the waiting period, the lung disease usually progress
[3]. As a result, patients' clinical condition worsens and quality of life decreases [4].

Pulmonary Rehabilitation (PR) has an important role in the management of comorbidities and complications in the lung transplantation process [5]. Dyspnea in this patient population is the primary symptom affecting quality of life. In our study, the effect of PR 
on dyspnea and factors related with dyspnea were investigated in lung transplant candidates. We believe that the determination of primary factors affecting dyspnea will be guiding the development of PR program design and the data obtained from our study will guide clinicians in which or which different PR components such as respiratory muscle strength, peripheral muscle strength or medication should be focused. In this way, we believe that patients' quality of life will increase.

\section{METHODS}

Our study is a retrospective, single center, selfcontrolled clinical trial. The records of the patients who listed lung transplantation and enrolled in the exercise program of Pulmonary Rehabilitation Centre between 2017-2019 were restrospectively reviewed. The study was approved by the local ethics committee (Protocol no: 1665). Signed informed consent was obtained from each patient prior to commencing the PR program for routine clinical procedure. The study was carried out in accordance with the Helsinki Declaration. The exercise programme included of aerobic and strengthening training.

\section{Aerobic Training}

The aerobic exercise program had included treadmill walking (15 sc), cycle training, arm ergometer training. Group exercises were performed in sets of 15 minutes each with three exercise modalities. During the exercises, oxygen saturation, heart rate, Borg fatigue and dyspnea scores, and distance covered were recorded. It was based on the target heart rate method $($ Target Heart Rate $=$ resting heart rate $+(\%$ Aerobic exercise intensity $\times$ heart rate reserve). The intensity of the exercise was progressively increased to $80 \%$ workload, starting with a $60 \%$ workload, with a limited symptom limit.

\section{Strengthening/Resistance Training}

It is recommended that resistance targets are set at loads equivalent to 20 to $40 \%$ of a 1 -repetition maximum (1RM) maneuver and performed between 8 to 12 repetitions for 1 to 2 sets per session. Exercises focused on biceps, triceps, quadriceps, hamstring and hip muscles. Dumbbles and free weights were used in training sessions.

\section{Outcome Measurements}

\section{Modified Medical Research Council (mMRC) Dyspnea Scale}

Dyspnea perceptions during the activities of daily living were assessed with modified Medical Research Council scale [6].

\section{Pulmonary Function Test}

It was conducted by using the Sensor Medics model 2400 (Yorba Linda, CA, USA), and according to the American Thoracic Society (ATS) guidelines 7].

\section{Six Minute Walking Test}

The test was conducted in a 30-meter corridor in line with American Thoracic Society (ATS) guidelines. Before and after the test, oxygen saturation, heart rate, Borg fatigue rating, and walking distance were recorded $[8,9]$.

\section{Maximum Inspiratory Pressure-Maximum Expiratory Pressure (MIP-MEP)}

The mouth pressure measurement was performed with the Micro-RPM ${ }^{\circledR}$ instrument from SensorMEDIC. Patient placed a rubber mouthpiece with flanges, on the device, sealed their lips firmly around the mouthpiece, exhaled/inhaled slowly and completely, and then tried to breath in as hard as possible [10]. The aim is that the variability between measurements is less than $10 \mathrm{~cm} \mathrm{H} 2 \mathrm{O}$. The maximum value was obtained [11].

\section{Peripheral Muscle Strength Measurement}

Handgrip measurements of the patient were performed. Upper and lower extremity muscle strength measurements were performed on the major muscles using a digital dinanometer (J-Tech Commander muscle testing device). Each measurement was repeated three times on the right and left extremities.

\section{Statistical Analysis}

Statistical analysis was conducted using SPSS (Statistical Package for Social Sciences Version IBM Statistic15.0. Chicago, IL, USA). The Shapiro-Wilk statistic was used to test the normality of the distribution of all variables. The Wilcoxon signed rank test was used to analyze the differences between the 
parameters. Variables were expressed as median (minimum-maximum). "The Pearson correlation test" was done to determine the correlation dyspnea perception and the other parameters. A $p<0.05$ was considered statistically significant.

\section{RESULTS}

The study included 47 patients with a mean age was $39 \pm 14.56$ years (range 15-68 years). The mean body mass index was $21.09 \pm 5.98 \mathrm{~kg} / \mathrm{m} 2$ and $34 \%$ (n =16) patients were female (Table 1). The diagnostic distributions were predominantly bronchiectasis (38\%) and chronic obstructive pulmonary disease (COPD) (11\%), but there were different pulmonary pathologies.

After PR, there were statistically significant improvements in 6 MWD $(p<0.0001)$, MIP $(p<$ $0.0001)$ and MEP $(p<0.0001), \mathrm{HG}(p<0.0001)$ and mMRC $(p<0$. 0001) (Table 2). There was no statistically significant correlation between the decrease in mMRC dyspnea score and in other outcome measures (Table 3 ).

\section{DISCUSSION}

Our study showed that PR has a positive effect on exercise capacity, peripheral and respiratory muscle strength and dyspnea in lung transplant candidates.
Table 1. Demographic information and diagnostic distributions of patients

\begin{tabular}{lc}
\hline $\begin{array}{l}\text { Age (years) } \\
\text { Gender }\end{array}$ & $39.38 \pm 14.56$ \\
\hline \multicolumn{1}{|c}{ Male, $\mathrm{n}(\%)$} & $31(66)$ \\
\hline Female, $\mathrm{n}(\%)$ & $16(34)$ \\
\hline BMI (kg/m2) & $21.09 \pm 5.98$ \\
Diagnosis, $\mathbf{n}(\%)$ & $1(2.1)$ \\
\hline Alveolarproteinosis & $18(38.3)$ \\
\hline Bronchiectasis & $5(10.6)$ \\
\hline Interstitiallungdisease & $1(2.1)$ \\
\hline Kartagener & $5(10.6)$ \\
\hline Cysticfibrosis & $11(23.1)$ \\
\hline COPD & $1(2.1)$ \\
RA lunginvolvement & $2(4.3)$ \\
\hline Sarcoidosis & $3(6.4)$ \\
\hline Silicosis & \\
\hline
\end{tabular}

Data are shown as mean \pm Standard deviation or $\mathrm{n}(\%)$. $\mathrm{BMI}=$ Body mass index, $\mathrm{COPD}=$ Chronic obstructive pulmonary disease, $\mathrm{RA}=$ Rheumatoid arthritis

But there was no relationship between these positive developments and dyspnea.

The dyspnea mechanism is not fully understood. In the studies conducted, it is reported that some neurological mechanisms may be responsible for this condition and may be caused by carbondioxide (CO2) reflex chemostimulation $[12,13]$. The patient

Table 2. Changes in study outcome measurements after pulmonary rehabilitation

\begin{tabular}{lccc}
\hline & Before PR & After PR & $\boldsymbol{p}$ value \\
\hline 6MWD $(\mathrm{m})$ & $337.51(42-548)$ & $419.40(84-629)$ & $<\mathbf{0 . 0 0 0 1}$ \\
FEV $_{1}(\%)$ & $33.47(10-64)$ & $34.56(10-98)$ & 0.435 \\
\hline FVC $(\%)$ & $41.04(6-75)$ & $42.64(21-78)$ & 0.267 \\
MIP $\left(\mathrm{cmH}_{2} \mathrm{O}\right)$ & $77.53(12-129)$ & $91.67(19-149)$ & $<\mathbf{0 . 0 0 0 1}$ \\
MEP $\left(\mathrm{cmH}_{2} \mathrm{O}\right)$ & $124.44(47-229)$ & $142.40(62-217)$ & $<\mathbf{0 . 0 0 0 1}$ \\
mMRC & $3(1-4)$ & $2(0-4)$ & $<\mathbf{0 . 0 0 0 1}$ \\
QF muscle strenght $(\mathrm{N})$ & $40.52(14-74)$ & $43.66(12-83)$ & 0.094 \\
HG & $61.73(30-108)$ & $66.93(30-125)$ & $<\mathbf{0 . 0 0 0 1}$ \\
\hline
\end{tabular}

Data are shown as median (minimum-maximum). $\mathrm{PR}=$ Pulmonary Rehabilitation, $6 \mathrm{MWD}=6$-minute walking test distance, $\mathrm{FEV1}=$ expiratoryvolume in $1 \mathrm{st}, \mathrm{FVC}=$ Challenging vital capacity, MIP $=$ maximal inspiratory pressure, $\mathrm{MEP}=$ maximal expiratory pressure, $\mathrm{mMRC}=$ Modified Medical Research Council dyspnoea score, $\mathrm{QF}$ $=$ quadriceps femoris, $\mathrm{HG}=$ handgrip force. The Wilcoxon signed rank test was used for $p$ values. 


\begin{tabular}{|c|c|c|c|c|c|c|c|}
\hline & $\triangle 6 M W D$ & $\triangle F^{\prime} V_{1}(\%)$ & $\Delta \mathrm{FVC}(\%)$ & $\Delta \mathbf{M I P}$ & $\triangle \mathrm{MEP}$ & $\begin{array}{c}\Delta \mathrm{QF} \\
\text { muscle } \\
\text { strenght }\end{array}$ & $\Delta \mathbf{H G}$ \\
\hline \multicolumn{8}{|c|}{$\Delta \mathrm{mMRC}$} \\
\hline $\mathbf{r}$ & -0.062 & -0.201 & -0.192 & -0.133 & 0.171 & -0.033 & -0.108 \\
\hline$p$ value & 0.679 & 0.186 & 0.206 & 0.379 & 0.249 & 0.827 & 0.476 \\
\hline
\end{tabular}

population in our study has terminal stage lung disease and it can be said at first glance that dyspnea is caused by $\mathrm{CO} 2$ increase. On the other hand, although there is no increase in lung functions as expected after the exercise program, the decrease in dyspnea severity of patients suggests that there may be different factors affecting this situation.

In a study examining the dyspnea mechanism in patients with interstitial lung disease and COPD, disease-specific differences in mechanical and respiratory muscle activity have been shown to not affect the relationship between the severity of dyspnea and the inspiratory neural drive to the diaphragm [14]. In our study, various patient groups with lung pathology were included. Similar gains were observed in all patients and dyspnea levels were decreased.

In all chronic respiratory diseases, the most important symptom with similar mechanisms is dyspnea [15]. In the literature, mMRC is widely used in dyspnea scoring. It has been reported that patients with dyspnea score between 3 and 5, who cause functional limitation should be referred to out patient PR programs $[16,17]$. In studies comparing PR with standard treatment, PR has been reported to decrease dyspnea more than standad treatment [18]. In our study, when the initial mMRC scores were above 3 , a significant reduction in dyspnea was achieved at the end of the program. This means that, before rehabilitation, patients experience shortness of breath when they walk for 100 meters or a few minutes, and at the end of the program they define a walking performance that is worse than their peers. Therefore, PR is an important treatment modality that normalizes the lives of these patients in the terminal period.
The rehabilitation practices during the waiting process take on the task of bridging the lung transpantation operation [19]. In a study examining the indicators of PR success in transplant candidates during the waiting process, it was demonstrated that short-term comprehensive exercise programs increase exercise capacity and quality of life regardless of the underlying disease [20]. In this particular and difficult population, exercise programs that are individualy planned, with symptom limited and appropriate exercise intensity should be arranged within the framework of the basic exercise program information [21]. The primary aim of our study was to determine the clinical characteristics affecting the level of dyspnea in individuals with advanced lung disease, and to determine the factors that have the potential to be improved by rehabilitation, and to guide the medication and exercise programs.

There are studies related to the increase of exercise capacity [22,23], respiratory muscle strength [22] and peripheral muscle strength in lung transplant candidates [24]. Similarly, in our study, exercise capacity, respiratory and peripheral muscle strength were increased by PR. Considering that patients have terminal stage lung disease, it is not possible to expect an improvement in pulmonary functions. Our study results support this situation. Reduction of dyspnea of patients whose pulmonary function values do not change indicates that different factors may be effective. On the other hand, in our analysis, we could not detect any relationship between the decrease in dyspnea and the change in other outcome measures. Further studies are needed to investigate the effect of different clinical features on rehabilitation outcomes. 


\section{Limitations}

Our limitations are the retrospective nature of the study and the relatively small number of patients. With more patients, prospective randomized controlled trials are needed.

\section{CONCLUSION}

As a result, PR improves exercise capacity, peripheral and respiratory muscle strength, and has a positive effect on dyspnea in lung transplantation candidates. Reduction of dyspnea, which is the most effective symptom of quality of life in this patient group, is an important gain. On the otherhand, there was no relationship between these positive developments and dyspnea in the clinical status of patients. Different factors that may affect dyspnea should be examined.

\section{Authors' contributions}

$\mathrm{EP}=$ designed study, performed study, collected data, analyzed data, wrote the paper; $\mathrm{AB}=$ performed study, collected data; and LK = wrote the paper

\section{Conflict of interest}

The authors disclosed no conflict of interest during the preparation or publication of this manuscript.

\section{Financing}

The authors disclosed that they did not receive any grant during conduction or writing of this study.

\section{REFERENCES}

1. Mathur S, Reid WD, Levy RD. Exercise limitation in recipients of lung transplants. Phys Ther 2004;84:1178-87.

2. Mathur S, Levy RD, Reid WD. Skeletal muscle strength and endurance in recipients of lung transplants. Cardiopulm Phys Ther J 2008;19:84-93.

3. Orens JB, Estenne M, Arcasoy S, Conte JV, Corris P, Egan JJ, et al. International guidelines for the selection of lung transplant candidates: 2006 update--a consensus report from the Pulmonary Scientific Council of the International Society for Heart and Lung Transplantation. J Heart Lung Transplant 2006;25:745-55.

4. Taylor JL, Smith PJ, Babyak MA, Barbour KA, Hoffman BM, Sebring DL, et al. Coping and quality of life in patients awaiting lung transplantation. J Psychosom Res 2008;65:71-9.

5. Picard C, Boisseau M, De Miranda S, Hamid A, Grenet D,
Parquin F, et al. [The management of lung transplantation candidates. A case series]. Rev Mal Respir 2015;32:1-7. [Article in French]

6. Munari AB, Gulart AA, Dos Santos K, Venancio RS, Karloh M, Mayer AF. Modified Medical Research Council Dyspnea Scale in GOLD Classification better reflects physical activities of daily living. Respir Care 2018;63:77-85.

7. Miller MR, Crapo R, Hankinson J, Brusasco V, Burgos F, Casaburi R, et al. General considerations for lung function testing. Eur Respir J 2005;26:153-61.

8. Brooks D, Solway S, Gibbons WJ. ATS statement on sixminute walk test. Am J Respir Crit Care Med 2003;167:1287.

9. Holland AE, Spruit MA, Troosters T, Puhan MA, Pepin V, Saey D, et al. An official European Respiratory Society/American Thoracic Society technical standard: field walking tests in chronic respiratory disease. Eur Respir J 2014;44:1428-46.

10. American Thoracic Society/European Respiratory S. ATS/ERS Statement on respiratory muscle testing. Am J Respir Crit Care Med 2002;166:518-624.

11. Wen AS, Woo MS, Keens TG. How many maneuvers are required to measure maximal inspiratory pressure accurately. Chest 1997; 111:802-7.

12. Burki NK, Lee L-Y. Mechanisms of dyspnea. Chest 2010;138:1196-201.

13. Buchanan GF, Richerson GB. Role of chemoreceptors in mediating dyspnea. Respir Physiol Neurobiol 2009;167:9-19.

14. Faisal A, Alghamdi BJ, Ciavaglia CE, Elbehairy AF, Webb $\mathrm{KA}$, Ora J, et al. Common mechanisms of dyspnea in chronic interstitial and obstructive lung disorders. Am J Respir Crit Care Med 2016;193:299-309.

15. Dyspnea. Mechanisms, assessment, and management: a consensus statement. American Thoracic Society. Am J Respir Crit Care Med 1999;159:321-40.

16. Evans RA, Singh SJ, Collier R, Williams JE, Morgan MD. Pulmonary rehabilitation is successful for COPD irrespective of MRC dyspnoea grade. Respir Med 2009;103:1070-5.

17. Garrod R, Marshall J, Barley E, Jones PW. Predictors of success and failure in pulmonary rehabilitation. Eur Respir $\mathrm{J}$ 2006;27:788-94.

18. Bolton CE, Bevan-Smith EF, Blakey JD, Crowe P, Elkin SL, Garrod R, et al. British Thoracic Society guideline on pulmonary rehabilitation in adults. Thorax 2013;68 Suppl 2:ii1-30.

19. Wickerson L, Rozenberg D, Janaudis-Ferreira T, Deliva R, Lo V, Beauchamp G, et al. Physical rehabilitation for lung transplant candidates and recipients: An evidence-informed clinical approach. World J Transplant 2016;6:517-31.

20. Kenn K, Gloeckl R, Soennichsen A, Sczepanski B, Winterkamp S, Boensch M, et al. Predictors of success for pulmonary rehabilitation in patients awaiting lung transplantation. Transplantation 2015;99:1072-7.

21. Mathur S, Hornblower E, Levy RD. Exercise training before and after lung transplantation. Phys Sportsmed 2009;37:78-87.

22. Pehlivan E, Mutluay F, Balci A, Kilic L. The effects of inspiratory muscle training on exercise capacity, dyspnea and respiratory functions in lung transplantation candidates: a randomized controlled trial. Clin Rehabil 2018;32:1328-39.

23. Pehlivan E, Balci A, Kilic L, Kadakal F. Preoperative 
pulmonary rehabilitation for lung transplant: effects on pulmonary function, exercise capacity, and quality of life; first results in Turkey. Exp Clin Transplant 2018;16:455-60.

24. Vainshelboim B, Oliveira J, Fox BD, Soreck Y, Fruchter O,
Kramer MR. Long-term effects of a 12-week exercise training program on clinical outcomes in idiopathic pulmonary fibrosis. Lung 2015;193:345-54. 